\title{
Getting students engaged
}

\section{Phil Race}

Visiting Professor: University of Plymouth, and higher education consultant based in Newcastle-upon-Tyne

\begin{abstract}
This short article homes in on seven straightforward factors which underpin student learning, and proposes some practical tactics we can use to address these factors in ways which can optimise student engagement in higher education. Reference is also made to assessment and feedback - which students say (for example in the UK National Student Survey) are relatively unsatisfactory elements of their experience of higher education, and the tactics proposed in this article address such concerns.
\end{abstract}

Keywords: student engagement; student experience; learning development.

\section{Introduction}

We live and work in challenging times. Now that it seems certain (post Browne, 2010) that the fees students pay for their higher education experience will double (or worse), we can't be surprised that the emphasis on 'the student experience' of higher education will intensify. Whether students are saddling themselves with ever-increasing amounts of debt to afford that higher education experience, or whether it is parents who foot the bill, the spotlight continues to focus ever more sharply on student satisfaction, alongside all available measures of the quality of student engagement in higher education. We already have league tables in which the reflection of the student experience as gained from the National Student Survey features prominently. And with diminishing budgets for teaching, class sizes are likely to continue to grow - in those disciplines where higher education survives least scathed. So how can we meet the challenge of 'getting students engaged'? 
'Engagement' is, however, not a one-way street. Students need to be engaged with us, and we need to find better ways of engaging with them, to help them to engage better with the curriculum they experience, and thereby invest in their success. So what kinds of learning development will help us - and our students - to square up to the challenges facing us? It is already clear that we can't leave it all to technology. E-engagement won't solve the problems - students clearly voice their expectations that they want to engage with their lecturers and tutors, not just with keyboards and websites. They can engage with technology without ever paying tuition fees. Technology is indeed a powerful tool, but learning needs to happen in brains and doesn't lend itself to being measured in broadband speeds, or other factors simply relating to the availability or flow of mere information.

Einstein said 'learning is experience - everything else is just information'. He also said 'it is simply madness to keep doing the same thing, and expect different results'. So to enhance student engagement in our rapidly changing higher education context, we need to be ready to try new things.

'Learning development is what higher education is arguably about. We have, however, for too long pursued dated and flawed ways of thinking about learning, as I argue at length in Making Learning Happen (Race, 2010) where I propose seven straightforward factors underpinning successful learning, as a result of asking over 100,000 people direct questions about their learning (good and bad) over the last couple of decades. Those who know my work on this will recognise the factors as:

1. Wanting to learn.

2. Taking ownership of the need to learn.

3. Learning by doing - practice, trial and error, repetition and experience.

4. Learning through feedback - praise, criticism, seeing the results, developing confidence.

5. Making sense of what is being learned - getting one's head round it (carefully avoiding the word 'understanding', which defies useful description and continues to develop over a lifetime).

6. Deepening learning by communicating it - explaining to others, coaching others, teaching others.

7. Making informed judgements - assessing one's own evidence of achievement and that of others - self- and peer-assessment. 
In this article, I suggest that in our mission to engage students and enhance the student experience, we can address each and every one of these seven factors in a purposeful and convergent way. I will take each factor in turn, and propose briefly three things we can set out to do to transform the student experience.

\section{Wanting to learn}

a) We need to face up to the fact that an important part of our job is to 'warm up' students' desire to learn successfully. Our job is no longer simply to make it possible for students to succeed, we need to help them to desire success.

b) We need to accept that there are some things that are trickier than others when it comes to 'wanting to learn'. Most subjects have their tough bits ('troublesome knowledge' or 'threshold concepts') where the want to learn is easily eroded. We need to share with students that these challenges are worth meeting.

c) We need to engage in dialogue with students so that we can keep track of their 'want' to learn, and respond accordingly when it wanes. End-of-module feedback questionnaires are far too late to find out how students' motivations are going, as indeed are end-of-programme National Student Survey data.

\section{Taking ownership of the need to learn}

a) We need to become much better at articulating the targets for students. Intended learning outcomes can - and should - help us to achieve this, when expressed clearly in language students can make sense of. We need to continually explain the evidence of achievement that we are going to be looking for in assignments, exam questions, and other assessment contexts. We need to demystify the targets, not veil them.

b) We need to address the 'so what?' in students' minds. Regarding each expectation regarding evidence of achievement of the outcomes, we need to have ready answers for students' questions such as 'what's in this for me?', 'what's the point of this exactly?', and 'why should I bother with this?'.

c) We need to approach teaching as a bid to 'make learning happen' for students. It's not enough to be masterful in the mere content being addressed. The key process is about helping students to get a grip on the content, so that they can in due course demonstrate convincingly that they have achieved the learning outcomes. 


\section{Learning by doing - practice, trial and error, repetition and experience}

a) We need to care more for what we get students to do, and worry less about what we do in our teaching sessions. For example, lectures need to involve students in trying things out, on their own and with each other, so that they begin to get their heads around complex ideas, rather than just go away with notes of what's in our minds about those ideas.

b) We need to help students to value the experience of getting things wrong then finding out why, and working towards getting them right. We need to help students to move away from getting things wrong being equated with failure.

c) We need to help students to see that ultimately it's 'what they do' that is the pathway to their qualifications, and not merely the amount of information they've stashed away on their laptops, in their files or in their heads. Assessment measures what students do with their pens, voices, hands and so on - and is often a poor measure of what's in their heads.

\section{Learning through feedback - praise, criticism, seeing the results, developing confidence}

a) We know from the National Student Survey in the UK that feedback is just about the least satisfactory element of the student experience of higher education. It comes too late, and (they say) isn't very useful at helping them. We need to stop doing the things that don't work, and start doing other things which may work better.

b) We need to make sure that feedback is a dialogue between ourselves and students, and not just a vain monologue from us to them (and too late anyway).

c) We need to maximise the potential of students getting feedback from each other, and giving feedback to each other, as ways of helping them to become much better at learning from feedback, and also helping them become more self-sufficient rather than depending on trying to please us.

\section{Making sense of what is being learned - getting one's head round it}

a) We need to face up to the fact that we can't do this for our students - they have to do this for themselves. That said, we need to do everything in our power to create 
the opportunity for them to really engage with the subject matter they are learning, so that they feel that they are gaining real mastery of it through their efforts.

b) We need to re-focus assessment so that we are seen to be valuing the extent to which students have made sense of topics, rather than merely measuring their fluency at regurgitating information about the subject matter they have learned.

c) We need to diversify assessment so that we're not just measuring (for example) what students can do with a pen in an exam room, or with their keyboards while writing essays and reports. We need to be better at triangulating our assessment processes to converge on how well they've got their heads around what they've learned.

\section{Deepening learning by communicating it - explaining to others, coaching others, teaching others}

a) We need to move students away from the belief that they are competing with each other, and toward the realisation that they can help each other to deepen their learning by talking about what they're learning, arguing about it, and discussing it.

b) We need to remind students that the measure of their learning is ultimately what they can communicate about what's in their heads, and that lots of practise communicating can maximise their potential to give of their best in assessmentrelated contexts such as exams and coursework.

c) We need to convince students that they can learn even more from each other than they can from us - especially when there's one of us and hundreds of them.

\section{Making informed judgements - assessing one's own evidence of achievement and that of others - self- and peer-assessment}

a) We know from the data from the National Student Survey in the UK that assessment is another of the least satisfactory elements of the student experience of higher education. We need to face up to the fact that students don't know how it really works, because it's something that's 'done to them'. We need to get them doing it.

b) We need to realise that for students assessment is 'the sharp end' of learning - the climax to which learning needs to lead. We need to get away from the 'sudden death surprises' of assessment, and prepare students systematically to show their optimum potential in each and every assessment context. 
c) We need to use self- and peer-assessment to help students to engage with their learning all the way through their studies, instead of assessment being something different at the end of some studying. Long gone are the days when a university degree was the passport to a life's career or vocation. We need to use assessment to train students to continue to be lifelong learners, assessing their own ongoing achievements as a natural part of learning.

As you will have seen in this discussion, student engagement depends on getting students engaged! But it also depends on us adjusting the things which we do, to cause that engagement to occur, rather than us simply to do our best at teaching and hope that they will do their best at learning. Addressing the factors which underpin successful learning is a way in to making both teaching and learning work optimally in the challenging environment we all face in higher education today.

\section{References}

Browne, J. (2010) Securing a sustainable future for higher education: an independent review of higher education funding and student finance. Available at: http://www.bis.gov.uk/assets/biscore/corporate/docs/s/10-1208-securingsustainable-higher-education-browne-report.pdf (Accessed: 11 February 2011).

Race, P. (2010) Making learning happen. $2^{\text {nd }}$ edn. London: Sage.

\section{Author details}

Phil Race is a Visiting Professor at the University of Plymouth, and Emeritus Professor of Leeds Metropolitan University. Supposedly retired now, he lives in Newcastle upon Tyne, when not on trains and planes to everywhere else to run sessions on assessment, learning and teaching! He is also a National Teaching Fellow and a Senior Fellow of the Higher Education Academy. Details of his work and beliefs (and loads of downloads) are available at his website www.phil-race.co.uk 